\title{
Preparation and properties of aromatic polyester/TiO nanocomposites from polyethylene terephthalate
}

\author{
Leonardo Moreira dos Santos ${ }^{a}$, Carlos Leonardo Pandolfo Carone ${ }^{a}$, Sandra Mara Oliveira Einloft $t^{a, b}$ \\ Rosane Angélica Ligabue ${ }^{a, b^{*}}$ \\ ${ }^{a}$ Graduation Program in Materials Engineering and Technology, \\ Pontifical Catholic University of Rio Grande do Sul - PUCRS, \\ 6681 Ipiranga Avenue, CEP 90610-900, Porto Alegre, Rio Grande do Sul, Brazil \\ ${ }^{b}$ School of Chemistry, Pontifical Catholic University of Rio Grande do Sul-PUCRS, \\ 6681 Ipiranga Avenue, 90610-900, Porto Alegre, Rio Grande do Sul, Brazil
}

Received: April 7, 2015; Revised: September 14, 2015; Accepted: November 26, 2015

\begin{abstract}
The development of polyester based materials with enhanced properties as well as the use of post- consumer plastics as raw material has been an increasing market demand. This work aims the synthesis and characterization of aromatic polyesters/titanium dioxide nanocomposites from PET and using $\mathrm{TiO}_{2}(0,1,3$ and $5 \% \mathrm{w} / \mathrm{w})$ as filler by in situ polymerization. The results obtained by DSC, XRD and FTIR analyzes evidenced an interaction between the $\mathrm{OH}$ groups on the $\mathrm{TiO}_{2}$ surface with the ester groups of the polymer leading to decrease of the polymer crystallinity and of hydrophilicity. By SEM images was possible to note a homogeneous distribution of the filler into polymer matrix with $1 \% \mathrm{w} / \mathrm{w}$ $\mathrm{TiO}_{2}$ (average particle size of $199 \mathrm{~nm}$ ), however for larger amounts of filler $\left(3\right.$ and $5 \% \mathrm{TiO}_{2}$ ) revealed the aggregates formation. The results showed an improvement of thermal properties and hardness of the nanocomposites containing $\mathrm{TiO}_{2}$ nanoparticles compared to pristine polyester.
\end{abstract}

Keywords: Nanocomposites, Aromatic polyester, Titanium dioxide, Filler, in situ polymerization.

\section{Introduction}

Polyesters (PE) are a class of polymers with great application in different market sectors, such as textile fibers ${ }^{1}$, engineering plastics ${ }^{2}$, specialty resins and elastomers ${ }^{3,4}$. Nowadays, the world production of polyester is one of the largest among the most common polymers, expected to reach about 40 million tonnes for $2015^{5}$.

On the other hand, the development of composites and nanocomposites polymer/filler can produce new materials with improved properties. The fillers or reinforcing materials have micro or nano scale and are dispersed into the polymeric matrix, having as main function to improve the barrier properties to gases and liquids ${ }^{6}$, physical-chemical ${ }^{7}$, thermal and mechanical properties ${ }^{8}$, among others. The improvement of these properties in nanocomposites materials is mainly due to the increased interaction between the filler particles and the polymer matrix, as a result of the higher surface area when compared to the traditional composites ${ }^{9}$. It is also known from the literature that the addition of fillers in the polymer matrix can enhance the biodegradation of the material allowing to find new application niches for these composites $^{10}$.

In preparing a nanocomposite, the interaction between the polymer matrix and fillers depends on the nature and the structure of the filler being used. Among the most studied filler materials are the metal oxides, clays, aluminum silicates

*e-mail: rligabue@pucrs.br with different kinds of forms (or habits), such as, layered, spherical and nanotubes ${ }^{11,12}$.

Polyesters are widely used because of its excellent processability, mainly when fillers are added ${ }^{13}$. The literature has described several studies on the preparation of aliphatic polyester nanocomposites with different inorganic fillers $\left(\mathrm{TiO}_{2}, \mathrm{Fe}_{2} \mathrm{O}_{3}, \mathrm{Al}_{2} \mathrm{O}_{3}\right)^{14}$, but few studies have been reported on the preparation of aromatic polyester nanocomposites with $\mathrm{TiO}_{2}$ as filler. The addition of $\mathrm{TiO}_{2}$ nanoparticles (rutile phase) in the polymeric matrix can improve properties such as anti-corrosion, anti-bactericidal, UV protection among others ${ }^{15}$. A recent work described the preparation of a non-woven PET hybrid nanocomposite on which was made the growth of $\mathrm{TiO}_{2}$ particles from the hydrolysis of $\mathrm{TiCl}_{4}{ }^{16}$.

In our study, we chose to use inexpensive raw materials to develop $\mathrm{TiO}_{2} /$ aromatic polyester new nanocomposites. The use of inexpensive raw materials such as plastics with a large disposal volume, e.g. post-consumer polyethylene terephthalate (PET) has great technological and commercial interest ${ }^{17,18}$. The choice of titanium dioxide $\left(\mathrm{TiO}_{2}\right.$, rutile phase) as filler is due to this compound being widely used in the industry, it has a low cost and their properties depend on the crystal structure, size and particle morphology. And the in situ method has been shown suitable for preparation of the nanocomposites of inorganic filler with polymer matrix because is a simple and inexpensive method and produces 
nanocomposites with good filler distribution in the polymer matrix $^{13,16}$.

In this context, the main goal of this work was to obtain aromatic polyester (APE) nanocomposites from polyethylene terephthalate (PET) and using different concentrations of titanium dioxide (rutile phase) by in situ polymerization searching for the best relation polymer/filler that can improve the nanocomposites properties (thermal stability, hardness and wettability) when compared to the polymeric matrix without filler.

\section{Experimental}

The synthesis reactions of polyester/ $/ \mathrm{TiO}_{2}$ nanocomposites via in situ polymerization were carried out in a glass reactor (500 $\mathrm{mL}$ ), equipped with pneumatic stirring, thermocouple column filled with glass rings, reflux condenser, with temperature control at the top and inert gas inlet $\left(\mathrm{N}_{2}\right)$. The synthesis was divided in two steps: 1) the synthesis of the prepolymer with the starting reactants; 2) the bulk polymerization under reduced pressure aiming to increase the molar weight of the polymer.

\subsection{In situ polymerization}

Into the reactor was added a mixture of dimethyl terephthalate (DMT- Quimpetrol) and polyethylene terephthalate (PET-M\&G), in the molar ratio 9:1. After that, a mixture of 1,4-butanediol (BD- Rudnik) and 1,6-hexanediol (HD- Rudnik) in the molar ratio 1:1 was added and the system temperature was increased to between $210-230^{\circ} \mathrm{C}$ for 2 hours and after the system was kept at $230^{\circ} \mathrm{C}$ under reduced pressure for 2 hours to increase the molar weight of the polymer. The dibutyl tin oxide (Miracema Nuodex) was used as catalyst $(0.1 \% \mathrm{w} / \mathrm{w}$ on total solids $)$ and 2,6 -di-tertbutyl-p-cresol (Merck, $0.05 \% \mathrm{w} / \mathrm{w}$ on total solids) as an antioxidant. The inorganic filler, $\mathrm{TiO}_{2}$ (Merck, 99\% rutile phase, average particle size $=166 \pm 35 \mathrm{~nm}$ ) was added at the beginning of the reaction in proportions of $1 \%, 3 \%$ and $5 \%$ relative to the total mass of solids (total weight of reagents). The filler was used without any treatment and it was dispersed in a hexanediol/butanediol mixture with the aid of an Ultra-Turrax disperser (12,000 rpm for 60min). To obtain the sample referred as pure polyester it was used the same reaction conditions without the addition of $\mathrm{TiO}_{2}$. In order to verify to possible role of $\mathrm{TiO}_{2}$ as a catalyst for the reaction, also it was performed a reaction with the addition of $5 \% \mathrm{w} / \mathrm{w}$ of $\mathrm{TiO}_{2}$ and without addition of the catalyst. At the end of the syntheses were obtained five samples named as: pure APE (pure aromatic polyester), APE 1, 3 and 5\% $\mathrm{TiO}_{2}$ (APE nanocomposites with different amount of $\mathrm{TiO}_{2}$ ), APE W/C (APE nanocomposite with $5 \% \mathrm{w} / \mathrm{w}$ of $\mathrm{TiO}_{2}$ and without catalyst for polymerization).

\subsection{Characterizations}

Fourier transform infrared spectroscopy/universal attenuated total reflectance (FTIR/UATR, PerkinElmer FTIR spectrometer model Spectrum 100) in the wave number from 4000 to 650 $\mathrm{cm}^{-1}$ was used to evaluate the matrix/filler interaction of the chemical bounding between the polymer and the filler. All samples were analyzed in the form of powder. Differential scanning calorimetry (DSC, TA Instruments model Q20 equipment) was used to measure the melting temperature $\left(T_{m}\right)$, the crystallization temperature $\left(T_{c}\right)$ and the melting and crystallization enthalpy $\left(\Delta \mathrm{H}_{m} ; \Delta \mathrm{H}_{c}\right)$. The DSC analyzes were performed in a temperature range from $-90^{\circ} \mathrm{C}$ to $220^{\circ} \mathrm{C}$ in two cycles (heating rate of $10^{\circ} \mathrm{C} / \mathrm{min}$ and a cooling rate of $5^{\circ} \mathrm{C} / \mathrm{min}$ ). It was weighed approximately $10 \mathrm{mg}$ of sample in hermetic aluminum pan. The thermal stability of the materials was analyzed by thermogravimetric analysis (TGA, TA Instruments Model SDT Q600). Assays were performed in a range of $25^{\circ} \mathrm{C}$ to $1000^{\circ} \mathrm{C}$ with a heating rate of $20^{\circ} \mathrm{C} / \mathrm{min}$, under nitrogen atmosphere and using a platinum sample holder. For the analysis it was used approximately $10 \mathrm{mg}$ of sample. The hardness test was carried out on specimens with dimensions $35 \times 48 \times 4 \mathrm{~mm}$. For this test it was used a device Woltest Sd 300, Shore A scale - Mainard "A" G112605. The analyzes were carried out in quintuplicate according to ASTM D2240. The XRD analyzes were performed on an apparatus Bruker Siemens D5000, using radiation $\mathrm{K} \alpha$ of the copper $(\lambda=1.542 \AA)$, voltage $40 \mathrm{KV}, 30 \mathrm{~mA}$, scanning between $2^{\circ}-30^{\circ} 2 \theta$ and scan speed of $0.02^{\circ} / \mathrm{min}$. The contact angle measurements were performed on the samples $\mathrm{APE} / \mathrm{TiO}_{2}$ nanocomposites and pure APE (dimensions: $35 \times 48 \times 4 \mathrm{~mm}$ ) in quadruplicate. All analyzes were carried out using milli-Q water in an equipment 15 + OCA and SCA202 software, version 3.12.11. Scanning electron microscopy (SEM) mode secondary electrons (SE), with a Philips model XL 30 with energy dispersive spectrometry (EDS) was used for evaluation of the surface morphology of the APE nanocomposites, as well as, the dimensions of the fillers and dispersion thereof in the polymer matrix. All the samples were fractured and metallized with a thin layer of gold. The data of the particle size and the clusters size were obtained by the digital program "Image Tool" (version 2, GPL). The average molar weights $\left(M_{n}\right.$ and $\left.M_{w}\right)$ and polydispersity index (PI) of the pure APE and nanocomposites were determined by gel permeation chromatography (GPC). The samples were solubilized in chloroform (PA, Vetec) at a concentration of $5.0 \mathrm{mg} / \mathrm{mL}$ (stirring for $15 \mathrm{~min}$ and after filtered with a PTFE membrane filter of 0.45 micrometers). The analyses were performed using a liquid chromatographer equipped with an isocratic pump-1515 (eluent: chloroform, flow: $1 \mathrm{~mL} / \mathrm{min}$ ) and refractive index detector (Waters Instruments-2414) with set of Styragel columns and polystyrene calibration standards.

\section{Results and Discussion}

\subsection{Characterization of the $\mathrm{APE} / \mathrm{TiO}_{2}$ nanocomposites}

In order to prove the composite formation and to evaluate the matrix /filler interaction, the polyester matrix and the obtained nanocomposites were analyzed by FTIR and DRX.

In Figure 1 is presented the infrared spectra of the $\mathrm{APE} / \mathrm{TiO}_{2}$ nanocomposites (in absorbance) and with a zoom in the region in $1710 \mathrm{~cm}^{-1}$ characteristic of the vibration of the carbonyl $(\mathrm{C}=\mathrm{O})$ of the ester group present in the polymer backbone. When the filler content increases, the intensity of this band decreases and its position is shifted toward lower wavenumber as an effect of the interaction of the $\mathrm{OH}$ groups on the $\mathrm{TiO}_{2}$ surface with the ester group of polymer 
matrix (Scheme 1). This behavior was also observed by Sudirman et al. (2012) for nanocomposites formed between aliphatic polyester resins and silica ${ }^{19}$ and Ghanem et al. (2014) for hyperbranched polyester/ $\mathrm{TiO}_{2}$ nanocomposites ${ }^{20}$.

Figure 2 illustrates the X-ray diffraction patterns of $\mathrm{TiO}_{2}$, pure $\mathrm{APE}$ and the synthesized $\mathrm{APE} / \mathrm{TiO}_{2}$ nanocomposites. The characteristic reflections of $\mathrm{TiO}_{2}$ (rutile phase) are situated at $27.5^{\circ} 2 \theta(d=3.24 \AA) ; 36^{\circ} 2 \theta(d=2.43 \AA) ; 54.3^{\circ} 2 \theta$

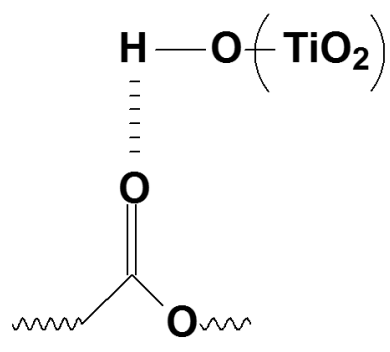

Scheme 1. Representation of the interaction filler-polymer.

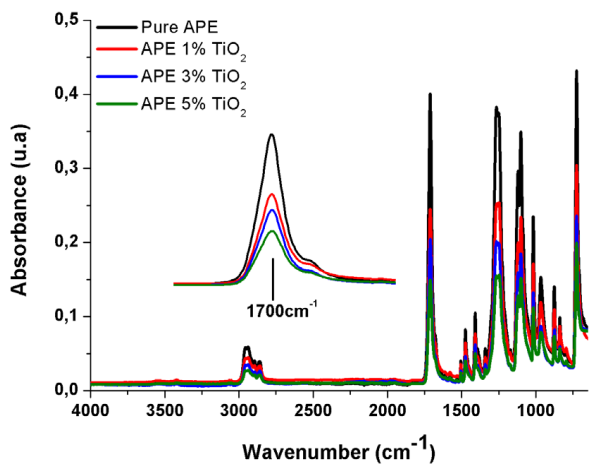

Fig. 1. FTIR Spectra of the pure APE, APE/TiO, nanocomposites with $1 \%, 3 \%, 5 \%$ of $\mathrm{TiO}_{2}$ and zoom in the region around $1700 \mathrm{~cm}^{-1}$.

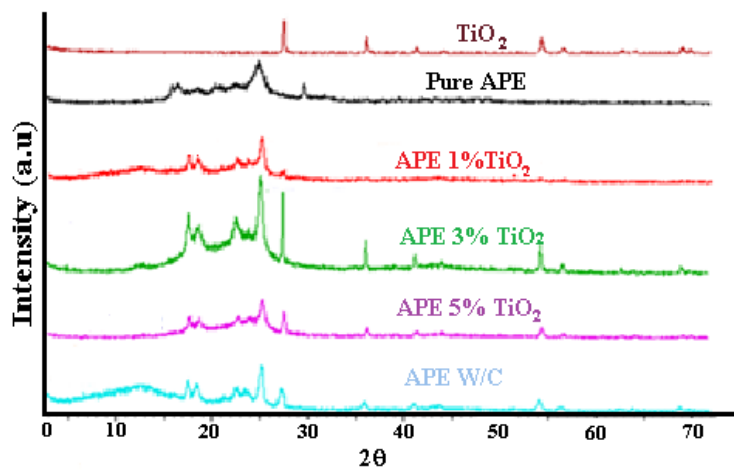

Fig. 2. XRD patterns of $\mathrm{TiO}_{2}$, pure APE, APE W/C and the $\mathrm{APE} / \mathrm{TiO}_{2}$ nanocomposites with $1 \%, 3 \%$ and $5 \% \mathrm{TiO}_{2}$.
( $d=1.68 \AA$ ), in agreement with the commercial $\mathrm{TiO}_{2}$ used to obtain the nanocomposites and the assignments described in literature $^{21,22}$. The X-ray diffraction pattern of the pure APE sample shows a broad region $\left(15^{\circ}-27^{\circ} 2 \theta\right)$ characteristic of semicrystalline polyester with one intense reflection at $24.5^{\circ}$ $2 \theta(d=3.57 \AA)$ and two diffraction peaks (less intense) at $16^{\circ}$ $2 \theta(d=5.60 \AA)$ and $16.5^{\circ} 2 \theta(d=5.39 \AA)$ are evidenced in agreement with the literature ${ }^{23}$. The $\mathrm{X}$-ray diffraction patterns of $\mathrm{APE} / \mathrm{TiO}_{2}$ nanocomposites obtained with different filler contents show the characteristic peaks of $\mathrm{TiO}_{2}$ and APE, that evidences the filler/polymer interaction. However, intensity and width of these reflections differ with the filler content. In the region $15^{\circ}-27^{\circ} 2 \theta$, characteristic peaks of pure APE become narrower when the amount of the filler content increases. This result indicates an effective interaction of the filler with the polymer matrix ${ }^{24}$. The peak at $27.5^{\circ} 2 \theta$, characteristic of $\mathrm{TiO}_{2}$, is surprisingly less intense and broader in the sample $\mathrm{APE} / \mathrm{TiO}_{2} 5 \%$ than in the sample $\mathrm{APE} / \mathrm{TiO}_{2}$ $3 \%$. A similar trend was observed previously by Silva et al. (2013) and was explained by sample heterogeneity ${ }^{24}$.

Regarding the XRD pattern of the sample named APE $\mathrm{W} / \mathrm{C}$, which was synthesized without the addition of dibutyl tin oxide, the characteristic peaks of pure APE are present that indicates that the $\mathrm{TiO}_{2}$ filler can also act as a catalyst.

In Table 1 are presented the molar weights and polydispersity index of the pure APE and the synthesized nanocomposites. Molar weights differ with the filler content: the molar average number $\left(M_{n}\right)$ and the molar average weight $\left(M_{w}\right)$ are lower than pure APE in the case of $1 \%$ of $\mathrm{TiO}_{2}$; however these values increase with higher filler content. It is believed that the interactions between the particles of $\mathrm{TiO}_{2}$ and the growing polymer chain limited the growth of the $\mathrm{APE}^{24}$. In the case of 3 and $5 \%$ of $\mathrm{TiO}_{2}$, the filler is probably also acting as a catalyst for esterification reaction, since titanium-based compounds are excellent catalysts for esterification and transesterification reactions ${ }^{23,25}$. The polydispersity index (PI) was around 2.0 that is a characteristic value of condensation polymerization. The molar weights obtained for APE $5 \% \mathrm{w} / \mathrm{w}$ $\mathrm{TiO}_{2} \mathrm{~W} / \mathrm{C}$ (Table 1) show that filler also act as catalyst.

The Figure 3 shows the DSC curves of the pure APE and the $\mathrm{APE} / \mathrm{TiO}_{2}$ nanocomposites. As with the pure APE, whatever the filler content two melting peaks (peak 1 and peak 2 in Figure 3a) and only one crystallization peak (Figure $3 b$ ) are observed.

Some studies evidenced the presence of double crystallite regions produced by different morphologies ${ }^{26,27}$. This behavior was observed in some flexibles semicrystalline polymers such as polyethylene $(\mathrm{PE})^{28}$, polypropylene $(\mathrm{PP})^{28}$ or semi-rigid polymer such as poly(ether-ether-ketone)

Table 1. GPC analysis of the pure $\mathrm{APE}$ and $\mathrm{APE} / \mathrm{TiO}_{2}$ nanocomposites with $1,3,5 \% \mathrm{TiO}_{2}$ and $5 \% \mathrm{TiO}_{2} \mathrm{~W} / \mathrm{C}$.

\begin{tabular}{cccc}
\hline $\mathrm{TiO}_{2}(\mathbf{\%})$ & $\boldsymbol{M}_{\boldsymbol{n}}(\mathbf{g} / \mathbf{m o l})$ & $\boldsymbol{M}_{\boldsymbol{w}}(\mathbf{g} / \mathbf{m o l})$ & $\mathbf{P I}$ \\
\hline 0 & 7495 & 12492 & 1.7 \\
1 & 5883 & 10655 & 1.8 \\
3 & 8802 & 17783 & 2.0 \\
5 & 9965 & 17836 & 1.8 \\
$5 \mathrm{~W} / \mathrm{C}$ & 1734 & 2756 & 1.6 \\
\hline
\end{tabular}



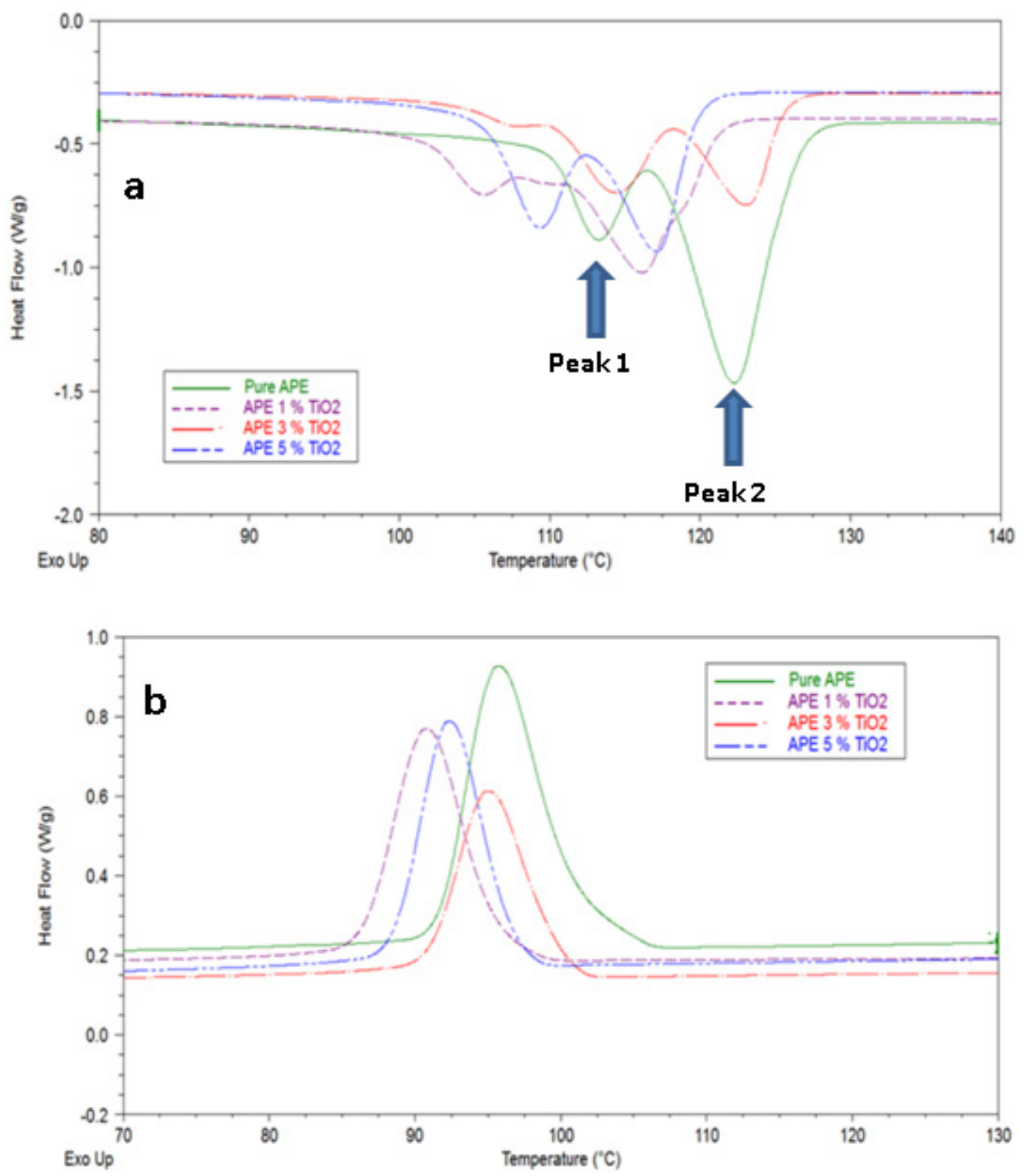

Fig. 3. DSC curves of pure $\mathrm{APE}$ and the $\mathrm{APE} / \mathrm{TiO}_{2}$ nanocomposites: (a) melting peak; (b) crystallization peak.

Table 2. Thermal properties and contact angle of the pure APE and $\mathrm{APE} / \mathrm{TiO}_{2}$ nanocomposites with $1,3,5 \% \mathrm{TiO}_{2}$ and $5 \% \mathrm{TiO} \mathrm{W}_{2} \mathrm{C}$.

\begin{tabular}{|c|c|c|c|c|c|c|c|c|c|}
\hline $\begin{array}{l}\mathrm{TiO}_{2} \\
(\%)\end{array}$ & $\begin{array}{l}\operatorname{Tm}_{1} \\
\left({ }^{\circ} \mathrm{C}\right)\end{array}$ & $\begin{array}{l}\mathrm{Tm} \\
\left({ }^{\circ} \mathrm{C}\right)\end{array}$ & $\underset{(\mathbf{J} / \mathbf{g})}{\Delta \mathbf{H m}_{l}}$ & $\underset{(\mathbf{J} / \mathbf{g})}{\Delta \mathbf{H m}}$ & $\begin{array}{c}T_{c} \\
\left({ }^{\circ} \mathbf{C}\right)\end{array}$ & $\begin{array}{l}\Delta \mathbf{H}_{c} \\
(\mathbf{J} / \mathbf{g})\end{array}$ & $\begin{array}{l}T_{\text {onset }} \\
\left({ }^{\circ} \mathbf{C}\right)\end{array}$ & $\begin{array}{l}T_{\text {endset }} \\
\left({ }^{n} \mathrm{C}\right)\end{array}$ & $\begin{array}{c}\text { Contact Angle } \\
\left({ }^{\circ}\right)\end{array}$ \\
\hline 0 & 113 & 122 & 6 & 29 & 96 & 51 & 393 & 434 & 58 \\
\hline 1 & 105 & 118 & 4 & 22 & 92 & 43 & 392 & 434 & 64 \\
\hline 3 & 115 & 124 & 10 & 9 & 93 & 34 & 393 & 433 & 65 \\
\hline 5 & 109 & 118 & 6 & 14 & 91 & 39 & 393 & 432 & 69 \\
\hline $5 \mathrm{~W} / \mathrm{C}$ & 93 & 104 & 3 & 15 & 82 & 31 & 178 & 476 & nd \\
\hline
\end{tabular}



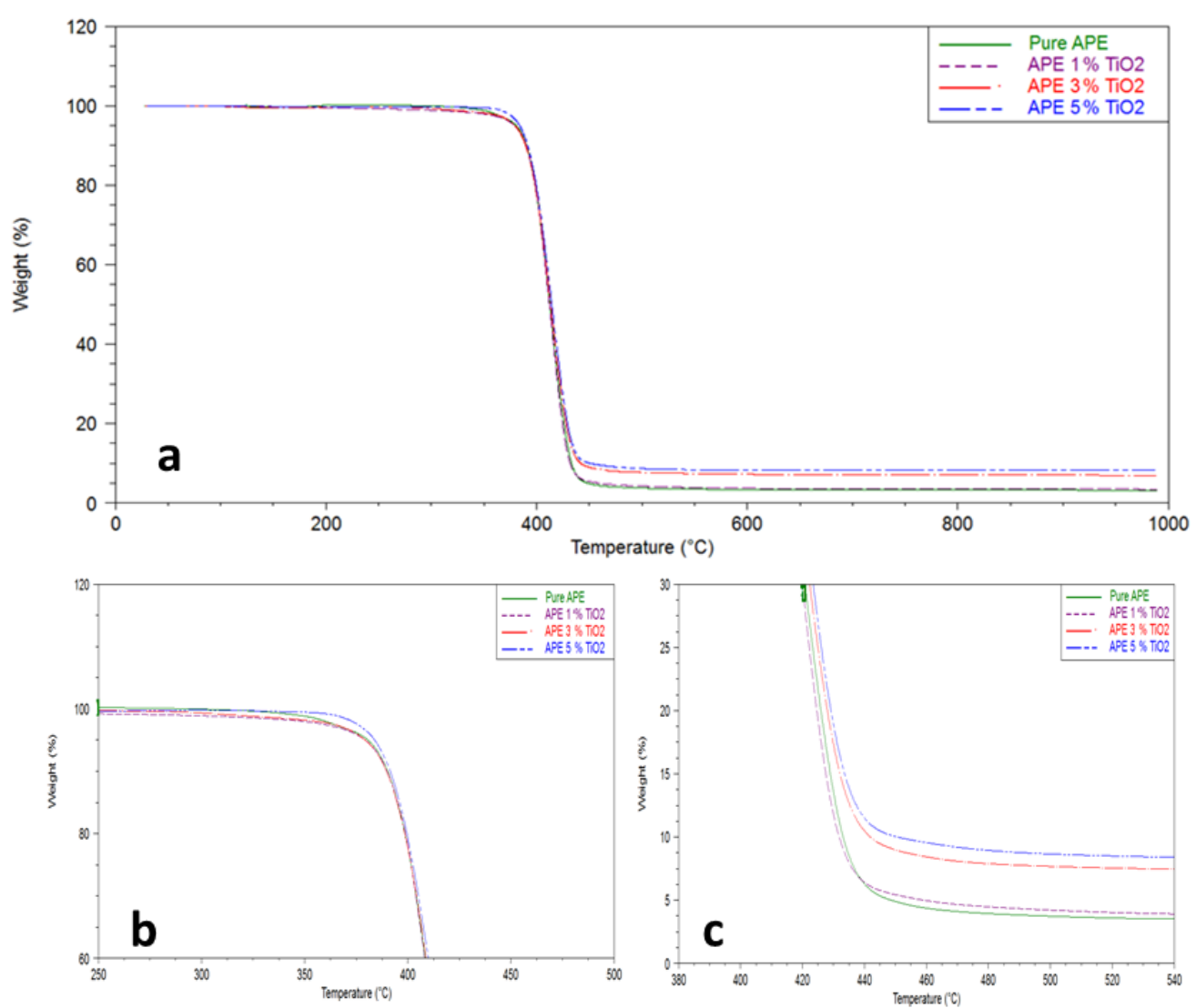

Fig. 4. Thermogravimetric analysis of the pure APE, APE with 1, 3 and $5 \% \mathrm{TiO}_{2}$ (a) initial region of degradation of APEs (b) and final region of degradation of APEs (c).

$(\mathrm{PEEK})^{29}$, poly (ethylene terephthalate) (PET) $)^{25}$, among others and can be explained by the formation of different morphologies associated with the crystallization process of these polymers. These materials can present two or more crystal modifications or, at least two groups with various lamellar structures, or even different crystalline morphologies ${ }^{25}$. These different structures can be formed in the isothermal crystallization process at temperatures much above the ambient $\left(70^{\circ} \mathrm{C}-100^{\circ} \mathrm{C}\right)$ as observed for the poly (alkylene succinate) $\left(80^{\circ} \mathrm{C}-100^{\circ} \mathrm{C}\right)^{26,27}$. In our study, at the end of the 2 nd stage of synthesis (bulk polymerization), the APE started to solidify at temperatures much above the ambient (around $90^{\circ} \mathrm{C}$ ). Besides that, the APE was formed by two linear aliphatic segments which could contribute to the formation of different crystalline regions. One single crystallization peak was observed and this behavior has been seen after the cooling process from the melt polymer ${ }^{23}$.

Table 2 shows the values of $T m_{1}, T m_{2}$ (melting temperatures of the peak 1 and peak 2, respectively) $\Delta \mathrm{Hm}_{1}, \Delta \mathrm{Hm}_{2}$ (fusion enthalpies of the peak 1 and peak 2 , respectively) and the values of $T_{c}$ (crystallization temperature) and $\Delta \mathrm{H}_{c}$ (crystallization enthalpy) obtained from the DSC curves (Figure 3 ) of the pure APE and $\mathrm{APE} / \mathrm{TiO}_{2}$ nanocomposites synthesized.

From the data shown in Table 2 it could be seen that the addition of different amounts of $\mathrm{TiO}_{2}$ did not significantly modify the melting temperatures of the polymers. However, there was a decrease in the melting enthalpy of peak 2 ,

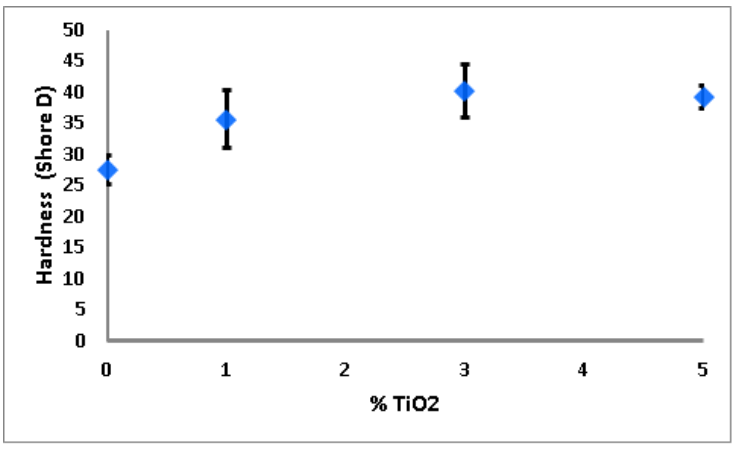

Fig. 5. Hardness of the $\mathrm{APE} / \mathrm{TiO}_{2}$ nanocomposites and the pure APE.

indicating a decrease in the population of crystallites associated with this peak. This result was also observed in the work of Yoo and Im $(1999)^{26}$.

The $T_{c}$ values for the nanocomposites showed a tendency to decrease when compared to the pure polymer sample (Table 2). On the other hand, there was a decrease in crystallization peak area (Figure $3 b$ ) resulting in a decrease of the $\Delta \mathrm{H}_{c}$, which corroborates with the results of the polymers crystallinity in the nanocomposites. This decrease in the crystallinity is a result of the filler-polymer interaction, which interferes 

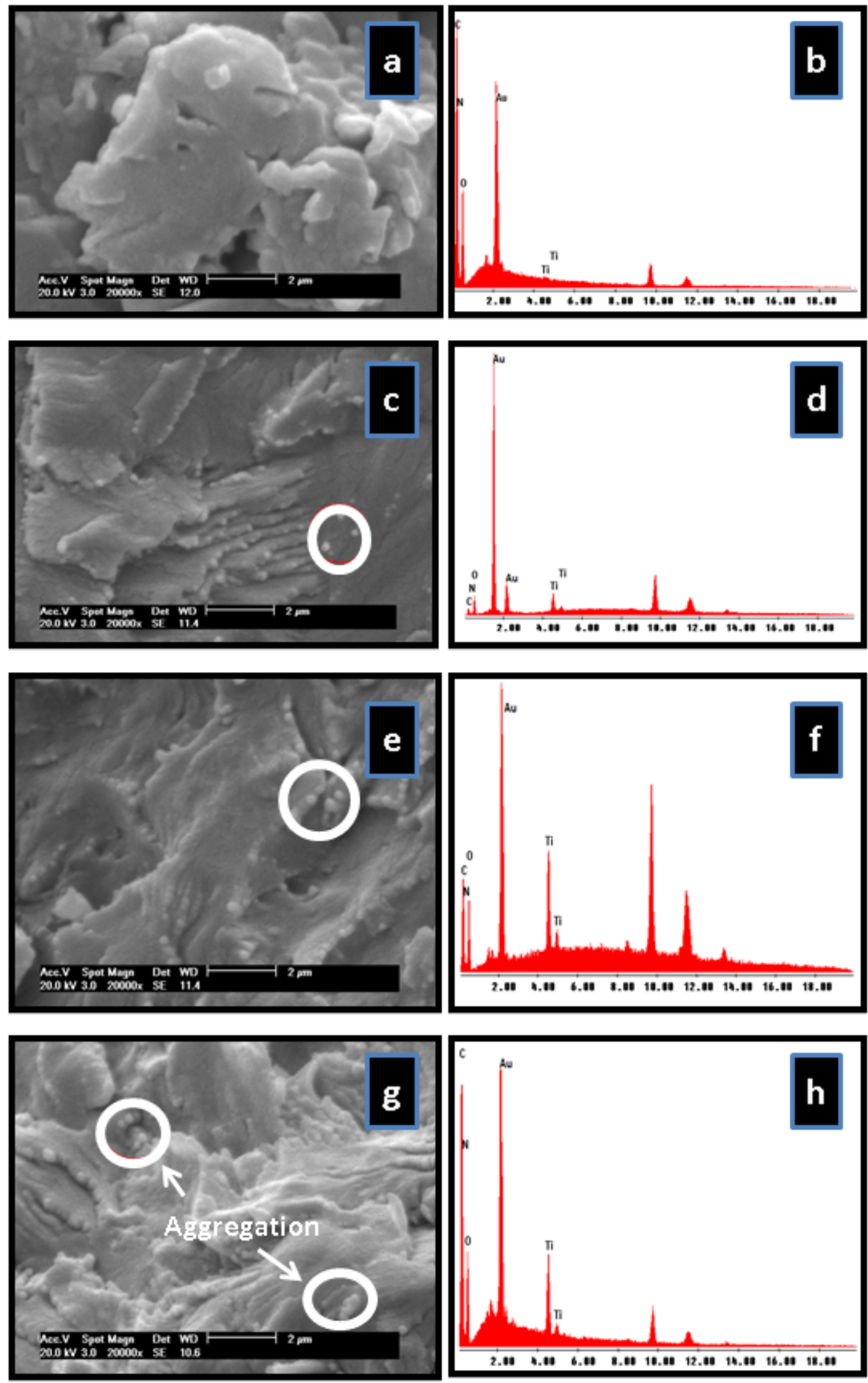

Fig. 6. Micrographs of the pure polymer (a); APE with 1\% (c); 3\% (e) and 5\% $\mathrm{TiO}_{2}$ (g). EDS spectra of the pure polymer (b); APE with $1 \%(\mathrm{~d}) ; 3 \%(\mathrm{f})$ and $5 \% \mathrm{TiO}_{2}(\mathrm{~h})$. 
in the organization between the chains the same way as it was observed by XRD.

The thermal degradation curves analyzed by TGA (Figure 4a) show a single stage of degradation, both for the pure polymer and for $\mathrm{APE} / \mathrm{TiO}_{2}$ nanocomposites. It was also not observed a change in the initial $\left(T_{\text {onset }}\right)$ and final $\left(T_{\text {endset }}\right)$ temperatures of the nanocomposites compared to pure APE (Table 2). However slight variations in start and end regions of degradation (Figures $4 \mathrm{~b}$ and $4 \mathrm{c}$, respectively) were observed, indicating that there was an interaction of $\mathrm{TiO}_{2}$ with the polymeric matrix, in agreement with reports in the literature ${ }^{30}$. It was also observed an increase in the residue content with the increase of filler added. For the APE $5 \% \mathrm{w} / \mathrm{w} \mathrm{TiO}_{2} \mathrm{~W} / \mathrm{C}$ was observed a $T_{m}, T_{c}, \Delta \mathrm{H}_{m}$ and $\Delta \mathrm{H}_{c}$ lower and $T_{\text {onset }}$ much more lower compared the other samples due the its low molar weight (Table 1).

Figure 5 presents the hardness results, where can be noted an increasing trend of this property in the APE/TiO 1 and $3 \%$ nanocomposites compared to the pure APE. However for $\mathrm{APE} / \mathrm{TiO}_{2} 5 \%$ was not observed the increase compared to $\mathrm{APE} / \mathrm{TiO}_{2} 3 \%$.

In a study performed by Yinghong et al. (2003) with unsaturated polyester/ $\mathrm{TiO}_{2}$ nanocomposites, was observed a maximum impact resistance when $4 \%$ of the filler was added and for higher percentage of $\mathrm{TiO}_{2}$, this property was decreased ${ }^{31}$. This behavior was explained by the agglomeration of fillers which cause stress points in the formed material ${ }^{24,31,32}$.
Figure 6 shows the micrographs of the pure APE and the APE/TiO $(1,3,5 \% \mathrm{w} / \mathrm{w})$. With $1 \%$ of $\mathrm{TiO}_{2}$ in the APE matrix, it can be seen a homogeneous distribution of the filler, indicating a good compatibility with the polymeric matrix. The diameter of the $\mathrm{TiO}_{2}$, inside the matrix, was around $199 \pm 58 \mathrm{~nm}$. On the other hand, it was observed clusters formation (in nanometer scale) in the materials with more than $1 \%$ of the charge (Figure $6 \mathrm{c}$ and $6 \mathrm{~d}$ ). This fact was evidenced by the larger average size in the nanocomposite, $263 \pm 96 \mathrm{~nm}$, since the untreated $\mathrm{TiO}_{2}$ used has an average diameter of $164 \pm 33 \mathrm{~nm}^{24}$. The same effect was verified by Sudirman et al. (2012), when silica was added in unsaturated polyester resin ${ }^{19}$ and by Silva et al. (2013) with polyurethane and $\mathrm{TiO}_{2}{ }^{24}$.

The EDS spectra of nanocomposites (Figure $6 \mathrm{~d}, 6 \mathrm{f}$ and $6 \mathrm{~h}$ ) evidenced an increase in the Ti peak compared to the pure polymer (Figure 6b) and confirm the incorporation of the $\mathrm{TiO}_{2}$ filler in the APE matrix.

The measurement of the contact angle is a way to prove the interaction between the polyester and the titanium dioxide, since the filler modifies the surface of the material and the wettability property (Figure 7). The filler addition promoted an gradual increase in the value of the contact angle of the droplet from $58^{\circ}$ (pure APE, Table 2$)$ to $69^{\circ}\left(\mathrm{APE} / \mathrm{TiO}_{2} 5 \%\right.$, Table 2$)$, indicating a decrease tendency of the hydrophilicity of the synthesized materials with larger amounts of the filler, when compared with the pure APE.

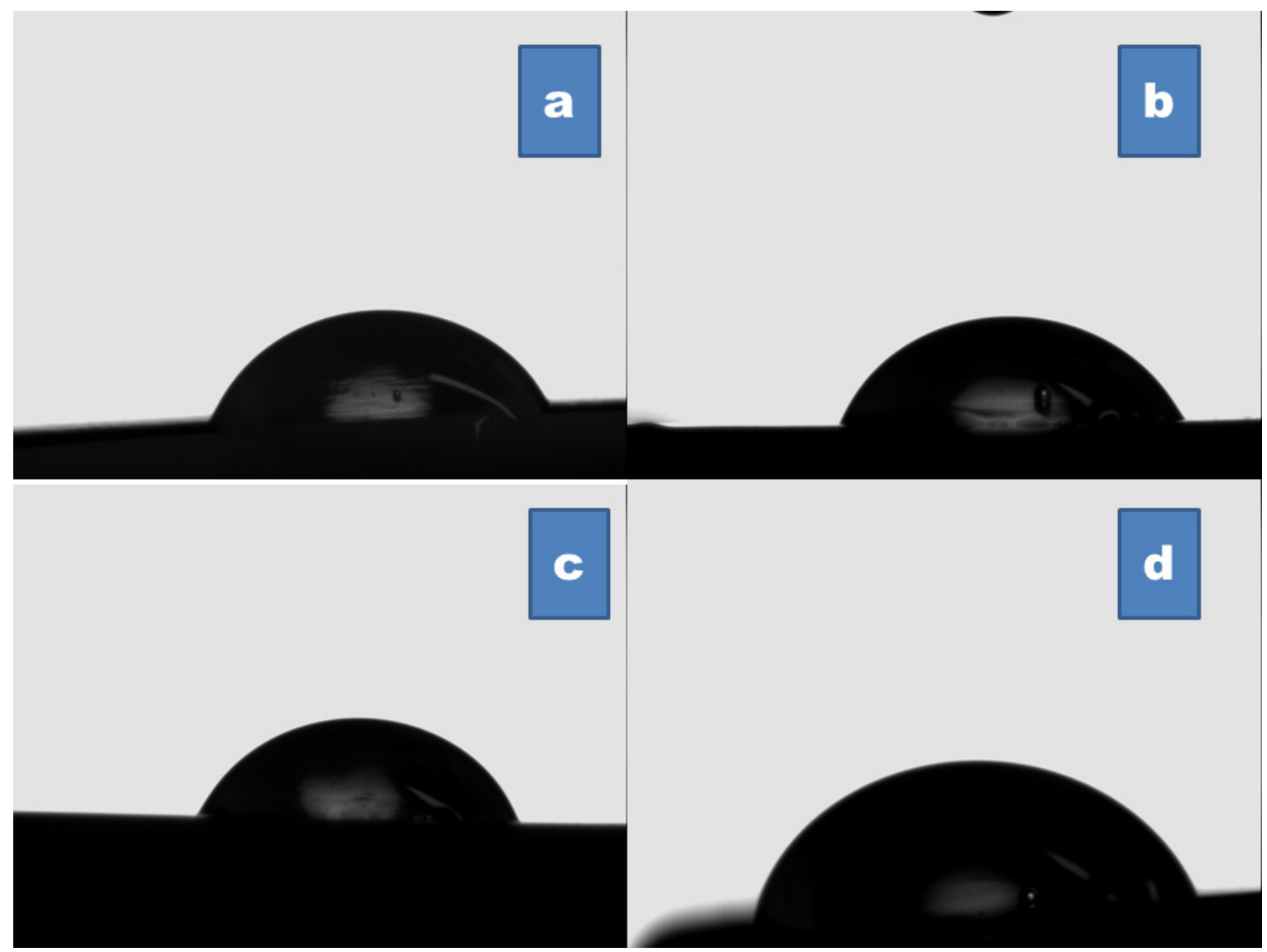

Fig. 7. Images of the contact angle of milli-Q water on the surface of pure APE (a) and the $\mathrm{APE} / \mathrm{TiO}$, nanocomposites with $1 \%$ (b), $3 \%$ (c) and $5 \% \mathrm{TiO}_{2}(\mathrm{~d})$. 


\section{Conclusions}

The nanocomposite $\mathrm{APE} / \mathrm{TiO}_{2}(1 \% \mathrm{w} / \mathrm{w})$ obtained by the in situ polymerization showed a homogeneous distribution of the filler in the polymeric matrix (average particle sizes of $199 \mathrm{~nm}$ ) and an improvement of thermal properties and hardness of the polyester matrix. However larger amounts of filler $\left(3\right.$ and $5 \% \mathrm{TiO}_{2}$ ) revealed the aggregates formation in the polymer matrix. The nanocomposites with the amount of filler equal to or exceeding 3\% presented molecular weight higher than the pure APE, indicating that the filler also acts as a catalyst for the polymerization reaction of the APE. The increasing addition of $\mathrm{TiO}_{2}$ promoted a slight increase of the contact angle and consequently a decrease tendency of the hydrophilicity of the $\mathrm{APE} / \mathrm{TiO}_{2}$ nanocomposites compared to pure APE.

\section{References}

1. Pinho EB, Da Costa HM, Ramos VD. Technical analysis of the use of polyester wastes in textile industry. Polimeros. 2013;23(5):654-660. http://dx.doi.org/10.4322/polimeros.2013.059

2. Wiebeck H, Harada J. Plásticos de Engenharia: tecnologia e aplicações. São Paulo: Artliber; 2005.

3. Shin, JH, Lee HK, Kim KM, Lee KH. Reactive compatibilization of an immiscible polyester/polyolefin blend with PP-g-MAH and PMPI dual compatibilizers. Journal of Applied Polymer Science. 2014;131(10):40232 (1-6).

4. Nakagawa T, Goto M. Recycling thermosetting polyester resin into functional polymer using subcritical water. Polymer Degradation and Stability. 2015;115:16-23.

5. Aizenshtein EM. Still no crisis for polyester fibres. Fibre Chemistry. 2010;42:1-9

6. Crétois R, Follain N, Dargent E, Marais J, Lebrun S, Crétois S, Follain L, Marais L, Lebrun L, Soulestin J, Bourbigot S, Marais S, Microstructure and barrier properties of PHBV/ organoclays bionanocomposites. Journal of Membranes Science. 2014;467:56-66.

7. Vargas M, Vázquez $H$, Guthausen G. Non-isothermal curing kinetics and physical properties of MMT-reinforced unsaturated polyester (UP) resins. Thermochimica Acta. 2015;611:10-19. Doi:10.1016;.tca.2014.12.024

8. Bidsorkhi HC, Soheilmoghaddam M, Pour RH, Adelnia H, Mohamad, Z. Mechanical, thermal and flammability of ethylene-vinyl acetate (EVA)/sepiolite nanocomposites. Polymer Testing. 2014;37:117-122. Doi:10.1016/polymerstesting.2014.05.007

9. Khali M, Saeed S, Ahmad Z. Mechanical and thermal properties of polyimide/silica hybrids with imide-modified silica network structures. Journal of Applied Polymer Science. 2008;107(2):12571268. DOI:10.1002/app.27149

10. Ray SS, Yamada K, Okamoto U. Polylactide-layered silicate nanocomposite: A novel biodegradable material. Nano Letters. 2002;2:1093-1096.

11. Esteves AC, Barros-Timmons A, Trindade T. Nanocompósitos de matriz polimérica: estratégias de síntese de materiais híbridos. Química Nova. 2004; 27(5):798- 806. http://dx.doi.org/10.1590/ S0100-40422004000500020

12. Chrissafisa K, Bikiaris DN. Can nanoparticles really enhance thermal stability of polymers? Part I: Anoverview on thermal decomposition of addition polymers. Thermochimica Acta. 2001;523(1):1-24.
The technique used (in situ polymerization) to produce aromatic polyesters with addition of $\mathrm{TiO}_{2}$ as a reinforcement was effective in the preparation of nanocomposites with improved thermal properties and hardness producing materials with different characteristics.

\section{Acknowledgements}

The authors would like to thank FINEP and CAPES for the financial support. SE and RL acknowledge CNPq for DT grant and CAPES for PNPD post-doc fellowship. LS thank Hewlett-Packard Brasil Ltda. for fellowship. FAPERGS-PRONEX, LAIF/PUCRS for FTIR and contact angle analyzes and LAPOL/UFRGS for hardness test.

13. Ollier R, Rodriguez E, Alvarez V. Unsaturated polyester/ bentonite nanocomposites: Influence of clay modification on final performance. Composites Part A: Applied Science and Manufacturing. 2013;48:137-143.

14. Bikiaris DN. Nanocomposites of aliphatic polyesters: An overview of the effect of different nanofillers on enzymatic hydrolysis and biodegradation of polyesters. Polymer Degradation and Stability. 2013;98(9):1908-1928.

15. Harifi T, Montazer M. Free carrier dyeing of polyester fabric using nano $\mathrm{TiO}_{2}$. Dyes and Pigments. 2013; 97(3): 440- 445.

16. Peng X, Ding E, Xue F. In situ synthesis of $\mathrm{TiO}_{2} /$ polyethylene terephthalate hybrid nanocomposites at low temperature. Applied Surface Science. 2012;258(17):6564-6570.

17. Lv J, Zhou Q, Liu G, Gao D, Wang C. Preparation and properties of polyester fabrics grafted with o-carboxymethyl chitosan. Carbohydrate Polymers. 2014;113:344-352.

18. Saikia N, Brito J. Waste polyethylene terephthalate as an aggregate in concrete. Materials Research. 2013;16(2):341350. http://dx.doi.org/10.1590/S1516-14392013005000017

19. Sudirman A, Budianto E, Gunawan, I. Synthesis and characterization of polyester-based nanocomposite. Procedia Chemistry. 2012;4:107-113. doi:10.1016/j.proche.2012.06.016

20. Ghanem A, Badawy A, Ismail N, Tian Z, Rehim M, Rabia A. Photocatalytic activity of hyperbranched polyester/TiO nanocomposites. Applied Catalysis A: General. 2014;472:191197. Doi: 10.1016/j.apcata.2013.12.023

21. Silva SS, Magalhães F, Sansiviero M. Nanocompósitos semicondutores $\mathrm{ZnO} / \mathrm{TiO}_{2}$. Testes fotocatalíticos. Quimica Nova. 2010;33(1):85-89. http://dx.doi.org/10.1590/S010040422010000100016

22. Filho CA, Zarbin A. Hollow porous carbon microspheres obtained by the pyrolysisof $\mathrm{TiO}_{2} /$ poly (furfuryl alcohol) composite precursors. Carbon. 2006; 44(14):2869-2876.

23. Zhu J, Cai J, Xie W, Chen PH, Gazzano M, Scandola M, Gross R. Poly(butylene 2,5-furan dicarboxylate), a biobased alternative to PBT: Synthesis, physical properties, and crystal structure. Macromolecules. 2013;46(3):796- 804.

24. Silva VD, Santos LM, Subda SM, Ligabue R, Seferin M, Carone CL, Einloft S. Synthesis and characterization of polyurethane/titanium dioxide nanocomposites obtained by in situ polymerization. Polymer Bulletin. 2013;70(6):1819-1833.

25. Pang, K, Kotek R, Tonelli A. Review of conventional and novel polymerization processes for polyesters. Progress in Polymer Science. 2006;31(11):1009-1037. 
26. Yoo, ES, Im SS. Meting behavior of poly(butylene succinate) during heating scan by DSC. Journal of Polymer Science Part B: Polymer Physics. 1999;37(13):1357-1366.

27. Papageorgiou GZ, Bikiaris DN. Crystallization and melting behavior of three biodegradable poly(alkylene succinates). A comparative study. Polymer. 2005;46(26) : 12081- 12095.

28. Toda A, Taguchi K, Nozaki K, Konishi M. Melting behaviors of polyethylene crystals: An application offast-scan DSC. Polymer. 2014;55(14):3186-3194.

29. Tardif X, Pignon B, Boyard N, Schmelzer JW, Sobotka V, Delaunay D, Schick C. Experimental study of crystallization of polyetheretherketone (PEEK) over a large temperature range using a nano-calorimeter. Polymer Testing. 2014;36:10-19.
30. Ersoy, M S, Onder E. Mechanical and thermal behaviors of polypropylene - multi-walled carbon nanotube nanocomposite monofilaments. Fibres \& Textiles in Eastern Europe. 2013;21(98):22-27.

31. Yinghong X, Xin W, Xujie Y, Lude L. Nanometre-sized $\mathrm{TiO}_{2}$ as applied to the modification of unsaturated polyester resin. Materials Chemistry and Physics. 2003; 77(2):609-611.

32. Ma XY, Zhang WD. Effects of flower-like ZnO nanowhiskers on the mechanical, thermal and antibacterial properties of waterborne polyurethane. Polymer Degradation and Stability. 2009;94(7):1103-1109. 